University of Nebraska - Lincoln

DigitalCommons@University of Nebraska - Lincoln

Public Health Resources

Public Health Resources

2011

Cryogenic zone compression for the measurement of dioxins in human serum by isotope dilution at the attogram level using modulated gas chromatography coupled to high resolution magnetic sector mass spectrometry

Donald G. Patterson, Jr.

EnviroSolutions Consulting, Inc, donpatt@etcmail.com

Susan M. Welch

Centers for Disease Control and Prevention

Wayman E. Turner

Centers for Disease Control and Prevention

Andreas Sjödin

Centers for Disease Control and Prevention

Jean-Francois Focant

University of Liège

Follow this and additional works at: http://digitalcommons.unl.edu/publichealthresources

Patterson, Jr., Donald G.; Welch, Susan M.; Turner, Wayman E.; Sjödin, Andreas; and Focant, Jean-Francois, "Cryogenic zone compression for the measurement of dioxins in human serum by isotope dilution at the attogram level using modulated gas chromatography coupled to high resolution magnetic sector mass spectrometry" (2011). Public Health Resources. 446.

http://digitalcommons.unl.edu/publichealthresources/446

This Article is brought to you for free and open access by the Public Health Resources at DigitalCommons@University of Nebraska - Lincoln. It has been accepted for inclusion in Public Health Resources by an authorized administrator of DigitalCommons@University of Nebraska - Lincoln. 


\title{
Cryogenic zone compression for the measurement of dioxins in human serum by isotope dilution at the attogram level using modulated gas chromatography coupled to high resolution magnetic sector mass spectrometry
}

\author{
Donald G. Patterson Jr. ${ }^{\mathrm{a}, *}$, Susan M. Welch ${ }^{\mathrm{b}}$, Wayman E. Turner ${ }^{\mathrm{b}}$, Andreas Sjödin $^{\mathrm{b}}$, \\ Jean-Francois Focant ${ }^{\mathrm{c}}$ \\ a EnviroSolutions Consulting, Inc., 172 Camelot Way, \#20198, Jasper, GA 30143, USA \\ ${ }^{\mathrm{b}}$ National Center for Environmental Health, Centers for Disease Control and Prevention, Atlanta, GA, USA \\ ' CART, Organic and Biological Analytical Chemistry, Mass Spectrometry Laboratory, Chemistry Department, University of Liège, Allée de la Chimie 3, \\ B-6c Sart-Tilman, B-4000 Liège, Belgium
}

\section{A R T I C L E I N F O}

\section{Article history:}

Available online 31 October 2010

\section{Keywords:}

Cryogenic zone compression (CZC)

Comprehensive two-dimensional gas

chromatography $(\mathrm{GC} \times \mathrm{GC})$

High resolution mass spectrometry (HRMS)

Dioxins

DDE

BB153

Human serum

Dried-blood spot (DBS)

\begin{abstract}
A B S T R A C T
A liquid nitrogen jet-cooled thermal modulator dedicated to comprehensive two-dimensional gas chromatography has been mounted in a GC oven coupled to a high resolution magnetic sector mass spectrometry instrument. The data acquisition parameters of the slow double-focusing magnetic sector MS instrument have been optimized to accommodate the description of the narrow modulated GC peaks. Acquisition rates were increased to $20 \mathrm{~Hz}$, while maintaining high mass resolution. Selected ion monitoring (SIM) descriptors, typically including several ions for both native and labeled analytes, were thus reduced to one or two to ensure enough MS cycle time. For maximization of the sensitivity enhancement due to cryogenic zone compression (CZC), the entire GC peak of interest was trapped and remobilized in one event. Optimization of the method resulted in the ability to detect low attogram (ag) amounts of 2,3,7,8-tetrachlorodibenzo-p-dioxin (2,3,7,8-TCDD) (313 ag gives a $\mathrm{S} / \mathrm{N}$ of 400:1), a level that had not yet been attained using classical GC-HRMS. An isotope-dilution calibration curve was constructed using ${ }^{13} \mathrm{C}_{12}-2,3,7,8$-TCDD as the internal standard over the range of $500 \mathrm{ag} / \mu \mathrm{L}$ to $35,000 \mathrm{ag} / \mu \mathrm{L}$ $\left(R^{2}=0.9953\right)$. Analyses of a standard natural human reference serum-matrix NIST SRM 1589a containing 223 ag of 1,2,3,7,8-pentachlorodibenzo-p-dioxin (1,2,3,7,8-PeCDD) (70\% recovery rate assumed) resulted in a peak with a $\mathrm{S} / \mathrm{N}$ of $188: 1$ (4 sigma, $m / z=355.8546$ ). Measurement of 2,2-bis (4-chlorophenyl-1,1,1-

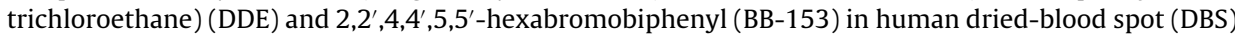
samples is also reported to illustrate the usefulness of such a sensitive technique. Finally, some of the challenges related to sample preparation, blank levels, and to the fact of measuring of such a limited number of molecules (less than 600,000 TCDD molecules) are discussed.
\end{abstract}

(c) 2010 Elsevier B.V. All rights reserved.

\section{Introduction}

For the last 25 years, background levels of polychlorinated dibenzo- $p$-dioxins (PCDDs), polychlorinated dibenzofurans (PCDFs), polychlorinated biphenyls (PCBs), and related persistent organic pollutants (POPs) in humans have declined to the point that their measurement has become increasingly difficult [1]. Improving sample preparation procedures to accommodate larger sample sizes has been carried out to a certain extent at the beginning of the last decade but these methods became of limited use because of the increasing demand to reduce the size of the specimen collected for human biomonitoring. Additionally, moving from

\footnotetext{
* Corresponding author. Tel.: +1 7062534666.

E-mail address: donpatt@etcmail.com (D.G. Patterson Jr.).
}

an invasive adipose tissue collection to a more readily available blood (serum) matrix also contributed to reducing the quantity of the lipophilic toxicants available for measurement due to the reduced lipid content of serum. From an analytical point of view, gas chromatography (GC) coupled to magnetic sector high resolution mass spectrometry (HRMS) is the most sensitive and specific technique in the field of ultra-trace measurement of halogenated toxicants. The use of isotope dilution (ID) based on ${ }^{13} \mathrm{C}$-labeled standards at a minimum mass resolution of 10,000 resolving power in the selected ion monitoring (SIM) acquisition mode, ensures enhanced selectivity and the lowest attainable sensitivity [2]. However, for the reasons listed above, more and more compounds are present at levels below the limits of detection (LODs) established using quality assurance/quality control $(\mathrm{QA} / \mathrm{QC})$ criteria. The analysis of data sets that include non-detectable values is a difficult task because several approaches are available and different 
approaches might lead to significantly different observations in environmental research [3]. Therefore, increasing the sensitivity of the state-of-the-art GC-IDHRMS measurement method is an area of considerable interest not only for analysts to report valuable congener-specific data but also for toxicologist who need a full picture to assess human exposure and the health impacts of these POPs.

The concept of thermal modulation in gas chromatography first appeared 25 years ago when Phillips and co-workers reported on 'Multiplex Gas Chromatography' [4]. The idea went forward and is now called 'comprehensive two-dimensional gas chromatography' (GC $\times$ GC), which is a hyphenated approach offering additional dimensionality over classical GC [5]. The major advantage of the technique is its capability to increase the peak capacity of the chromatographic separation which can be as high as the product of the peak capacities of the two individual columns that are made of orthogonal GC stationary phases [6]. GC $\times$ GC is therefore increasingly used when complex mixtures of compounds have to be separated such as in the case of petroleum analysis [7], flavour and fragrance characterisation [8], forensic investigations [9], environmental measurements [10], food control [11], and human biomonitoring [12]. Another breakthrough benefit of GC $\times$ GC is that the detectability limit can be up to 2-20 times better than single dimensional GC due to the signal-to-noise ratio enhancement related to thermal modulation [13-19]. Therefore, modulators can also have some potential applications as signal enhancers, as well as peak capacity enhancers.

In the early days of the GC $\times$ GC technique, two-stage thermal desorption modulators (TDM) consisted of fragile GC capillary columns carefully covered by electrically conductive paint to which electrical current pulses were applied at constant time interval [20]. Since then, efforts have been dedicated to the production of more robust non-moving modulators capable of performing with no excessive downtime. Among the different ones, gas jet based thermal modulators appeared to be the most efficient. A previous report describes the use of a quad-jet modulator installed on a GC coupled to a time-of-flight (TOF) MS for both peak capacity and signal enhancement in the isotope-dilution measurement of 59 selected POPs in human serum and milk [12]. Quadruple- and dual-jet configuration systems [21,22] later evolved into a simple, rugged, and reliable device named the loop modulator [23]. This jet-cooled modulator consists of one cold and one hot jet mounted perpendicular to each other. The dual stage modulation is achieved by looping the modulation tube so that it passes twice in the cold jet path. Remobilization of the cryo-trapped compounds occurs on both spots simultaneously when the hot jet is fired.

In the mid 1990s, because it was already expected that thermal modulation coupled with a magnetic sector mass spectrometer would result in an instrument offering the ultimate attainable sensitivity for measurement of these compounds, scientists at the Centers for Disease Control and prevention (CDC) attempted the coupling of GC $\times$ GC to HRMS for the measurement of PCDD/Fs and related contaminants in human serum [24,25]. Promising data were produced at the attogram level but the use of unreliable TDM and other rotating heated arm modulators limited the practical application of the method. In the present report, we revisited the coupling using the jet-cooled loop modulator for the measurement of ultra-trace levels of PCDD/Fs in human serum samples by means of cryogenic zone compression (CZC) GC-IDHRMS. We did not use a different stationary phase and secondary oven for the second dimension separation as in true GC $\times$ GC, we could have done so, and we chose rather to simplify the experiments by just incorporating modulated cryofocusing on the same columns to concentrate the analytes and lower the detection limits.

\section{Experimental}

\subsection{Standards and samples}

Dioxin standards were from Cambridge Isotope Laboratories (Andover, MA, USA) and were diluted with nonane to the following concentrations (in $\mathrm{fg} / \mu \mathrm{L}$ ) of $2,3,7,8$-tetrachlorodibenzo- $p$ dioxin (2,3,7,8-TCDD) and 1,2,3,7,8-pentachlorodibenzo-p-dioxin (1,2,3,7,8-PeCDD): 20, 10, 5, 2.5, 1.25, 0.625, 0.313, 0.157. Standards of 2,2-bis (4-chlorophenyl-1,1,1-trichloroethane) (DDE, a metabolite of DDT) and 2,2',4,4',5,5'-hexabromobiphenyl (BB-153) were obtained from Cambridge Isotope Laboratories.

Serum samples were multiple aliquots of National Institute of Standards and Technology Standard Reference Material 1589a (NIST SRM 1589a; PCBs, Pesticides, and Dioxins/Furans in Human Serum, August 9, 2000). The sample preparation method has been described previously [26]. Briefly, serum samples were mixed with internal standards for $30 \mathrm{~min}$. One volume of formic acid and one volume of water were added and the mixture was gently swirled. The solid-phase extraction (SPE) cartridges were conditioned with two volumes of methanol and two volumes of water. The sample mixture was then added through the activated SPE cartridges at $5 \mathrm{~mL} / \mathrm{min}$. One volume of water was then added to the cartridge before pumping to dryness at 10 psi for one hour. The elution of the SPE cartridges was carried out using three volumes of hexane. The extracts were further cleaned-up and fractionated using an automated strategy [27]. It consisted in low pressure liquid chromatography based on acidic silica, basic alumina, and carbon dispersed on Celite. The dioxin fraction resulted from the elution of the carbon column by $50 \mathrm{~mL}$ of toluene. It was concentrated and solvent exchanged to nonane, with a final volume of $5 \mu \mathrm{L}$.

Samples prepared from $10 \mathrm{~g}$ aliquots of NIST SRM 1589a were reconstituted in $20 \mu \mathrm{l}$ of nonane and diluted to the following approximate concentrations (based on NIST reference values corrected assuming $70 \%$ recovery for the sample preparation procedure) of 2,3,7,8-TCDD (in fg/ $\mu \mathrm{L}$ ): 6.50, 1.63, 1.30, 1.10, 0.81, 0.65, $0.54,0.41,0.33,0.21,0.16$. Subsequent experiments samples were prepared from aliquots of NIST SRM 1589a, ranging from 1 to $5 \mathrm{~g}$ and reconstituted in 5 or $10 \mu \mathrm{L}$ of nonane.

\subsection{CZC-GC-IDHRMS and GC-IDHRMS analysis}

For CZC-GC-IDHRMS, the gas chromatograph was a 6890N (Agilent Technologies, Palo Alto, CA, USA) operated in splitless mode and the mass spectrometer was a MAT95XP (ThermoElectron, Bremen, Germany). For CZC-GC, the column used for dioxin measurement was a DB-5 (Agilent, $7 \mathrm{~m} \times 0.1 \mathrm{~mm}$ i.d. $\times 0.1 \mu \mathrm{m} d_{\mathrm{f}}$ ) and for measurement of DDE and BB-153, a DB-5 (Agilent, $5 \mathrm{~m} \times 0.1 \mathrm{~mm}$ i.d. $\times 0.1 \mu \mathrm{m} d_{\mathrm{f}}$ ) was employed. The modulation device was the loop modulator from Zoex Corporation (Houston, TX, USA) which utilizes liquid nitrogen as the cryogen and consists of one cold jet and one hot jet with 2 loops of column passing through the jets, effectively creating a quadruple jet or dual-stage system [23]. The modulator was positioned approximately $75 \mathrm{~cm}$ from the exit end of the column. The modulation period for the maximum sensitivity enhancement was either 6 or $9 \mathrm{~s}$ for dioxins and $5 \mathrm{~s}$ for DDE and BB-153, and the hot jet pulse time was $800 \mathrm{~ms}$ for dioxin, $600 \mathrm{~ms}$ for DDE and BB-153. For resolution of all congeners of a given class, faster modulation cycles were employed.

Conventional GC-HRMS was performed using a ThermoMAT95XP or DFS and a 6890N GC using a HT-5 (SGE, $30 \mathrm{~m} \times 0.25 \mathrm{~m}$ i.d. $\times 0.1 \mu \mathrm{m} d_{\mathrm{f}}$ ) for BB-153 or a DB5-MS (Agilent, $30 \mathrm{~m} \times 0.25 \mathrm{~m}$ i.d. $\times 0.25 \mu \mathrm{m} d_{\mathrm{f}}$ ) for $2,3,7,8-\mathrm{TCDD}$ or DDE, under conditions described previously [28].

Mass spectrometry was performed in electron ionization (EI) mode at 10,000 resolution using selected ion monitoring (SIM) with 
one multiple ion detection (MID) group per congener class. Cycle times ranged from 40 to $70 \mathrm{~ms}$ ( 14 to $25 \mathrm{~Hz}$ ). The ion source temperature was $270^{\circ} \mathrm{C}$, trap current was $0.65 \mathrm{~mA}$ and electron energy was $40 \mathrm{eV}$. Data analysis and visualization was performed using ThermoElectron XCalibur and GC Image software. Quantification was performed using GC Image software (Lincoln, Nebraska, USA).

\section{Results and discussion}

\subsection{Optimization of CZC-GC-IDHRMS parameters}

Since the peaks resulting from GC $\times$ GC using cryogenic modulation are extremely narrow, and the data acquisition on the double-focusing magnetic sector mass spectrometer is much slower than detection methods typically used with the $\mathrm{GC} \times \mathrm{GC}$ technique, a number of adjustments had to be made to couple these two very sensitive techniques. No secondary oven was used, which meant that the peaks, while still very narrow, were wider than those often seen when GC $\times$ GC is used with more typical detectors. Another feature that distinguishes the work described in this paper from the typical approach to GC $\times$ GC is that in this work, only one column was used and the modulation was performed near the end of the analytical column. Such a system lacks the orthogonality typically deemed necessary for GC $\times$ GC, but even with this onecolumn only system a slight improvement of the separation in the 'second dimension $\left({ }^{2} \mathrm{D}\right)$ ' is observed, most probably to be related to the decreased peak width.

For sensitivity enhancement by GC with thermal modulation, the largest increase is obtained when the entire peak of interest is trapped and remobilized in one event or "slice". For this reason relatively long modulation times were used. Although such an approach endangered the respect of the conservation rule by potentially re-combining species chromatographically separated prior to modulation, it optimizes the signal enhancement effect. Additionally, the use of HRMS can, in most cases of coelution, selectively differentiate between target analytes and co-eluters. GC separation conditions have, nevertheless, to be carefully studied to avoid situations where isobaric species could closely elute and potentially pollute mass spectra and quantification.

Because of the lack of orthogonality, and because of the remobilization in one event or "slice", it appeared to be more appropriate to report the technique in terms of cryogenic zone compression $(\mathrm{CZC})$ rather than true $\mathrm{GC} \times \mathrm{GC}$.

Peak widths under the conditions used were typically in the $300-400 \mathrm{~ms}$ range when measured at peak base $(200-250 \mathrm{~ms}$ at half-height). Based on the accepted minimum need of at least seven data points across the GC peak for proper description of the Gaussian shape [29], the acquisition rate of the slow scanning sector MS instrument had to be sped up. This was quite a challenge knowing that the classical acquisition rate for the magnetic sector GC-IDHRMS approach is around one $\mathrm{Hz}$ (cycle time of approximately $1000 \mathrm{~ms}$, see Table 1). Basic MS parameters were thus optimized to reach acquisition rates of up to $20 \mathrm{~Hz}$ ( 7 data points across a $350 \mathrm{~ms}$ peak width, cycle time of approximately $45 \mathrm{~ms}$, see Table 1), while maintaining the required high mass resolution.

Table 1

Selected ion monitoring (SIM) descriptor for GC-IDHRMS and CZC-GC-IDHRMS

\begin{tabular}{lcc}
\hline TCDD window & GC-IDHRMS & CZC-GC-IDHRMS \\
\hline Number of monitored ions & 15 & 3 \\
Target dwell time (ms) & $15-100$ & 10 \\
Lock mass dwell time (ms) & 50 & 2 \\
Electric jump time (ms) & 10 & 6 \\
Cycle time (ms) & 1100 & 44 \\
Scan rate & $\sim 1 \mathrm{~Hz}$ & $\sim 20 \mathrm{~Hz}$
\end{tabular}

For classical routine HRMS dioxin methods where several chlorination levels can be monitored in a same SIM window, and where at least two ions are followed for both native analytes and isotopically labeled analytes, it is common to monitor up to 15 different ions. For CZC-GC-IDHRMS, the mass spectrometer method was constructed in such a way that each analyte or congener class was monitored in a separate group in the SIM descriptor. Also, only one ion was monitored for each of the ${ }^{13} \mathrm{C}$-labeled internal standards so that longer dwell times were available to monitor the targeted native ions. These two major modifications allowed target dwell time values of $10 \mathrm{~ms}$ instead of classically $15-100 \mathrm{~ms}$ (Table 1 ).

Some additional adjustments to the mass spectrometric parameters were necessary to optimize the conditions. For example, the lock and calibration masses were only monitored once every 50 cycles, and the dwell times on the lock and calibration masses were set to the minimum possible value of $2 \mathrm{~ms}$. Although the loss of the lock mass can easily be a major issue during HRMS analysis of dioxin, especially for challenging matrices, no noticeable increase in lock mass loss frequency was recorded, due to the very short time spent to measure it, even for analysis of real serum samples. Also, the time allowed for the electric jumps between ions within the MID group was reduced from the default time of $10 \mathrm{~ms}$ to a time of $6 \mathrm{~ms}$, which appeared to be long enough to ensure proper performance. This demonstrated the ruggedness of the MS sector instrument in terms of noise management and stability of even extremely set parameters. The optimization of the sector instrument parameters resulted in cycle times of $44 \mathrm{~ms}$, which resulted in scan rates higher than $20 \mathrm{~Hz}$. These features maximized the dwell times to achieve maximum sensitivity for the native ions under the rapid scanning conditions that were required for the CZC experiments.

\subsection{CZC-GC-IDHRMS of PCDDs in standards and serum samples}

When performing human biomonitoring for dioxin and dioxinlike compounds, it is extremely common to work on very limited specimen sizes, e.g. a few $\mathrm{mL}$ of blood. Combined with the fact that human levels are decreasing in industrialized societies, levels below the ultra-trace range are often targeted for many congeners. This is especially the case for the most toxic (TEFs $=1$ ) congeners like 2,3,7,8-TCDD and 1,2,3,7,8-PeCDD [30], which are often reported as non-detected. Because of this, the decision was made to initially concentrate efforts on sensitivity enhancement for 2,3,7,8-TCDD and 1,2,3,7,8-PeCDD, although other congeners were also monitored.

Optimization of the method for sensitivity enhancement of these two congeners resulted in the ability to detect low attogram (ag) amounts of these compounds. Fig. 1 shows the chromatogram resulting from an injection of a standard of $1 \mathrm{fg}$ of native $2,3,7,8$ $\operatorname{TCDD}(\mathrm{S} / \mathrm{N}=1420: 1)$ for the $\mathrm{M}+2$ ion of $m / z=321.8936 \mathrm{amu}$. When the system operates at maximal sensitivity, i.e. clean ion source and relatively new GC column, standards lower than $1 \mathrm{fg}$ can be detected under these conditions. For example, approximately 313 ag of 2,3,7,8-TCDD (Fig. 2) gives a S/N of 400:1 (4 sigma). This had not yet been reported using classical GC-IDHRMS. A similar sensitivity enhancement was observed for 1,2,3,7,8-PeCDD (not shown).

Careful dilutions of the lowest concentrations of commercially available 2,3,7,8-TCDD standards created a calibration standard set that was used to assess the linearity of the measured peak volume of the $m / z 321.8936$ ion versus concentration. An acceptable linear response was obtained $\left(R^{2}=0.9859\right)$ for a $1 \mu \mathrm{L}$ injection of the standards over a range of $313 \mathrm{ag} / \mu \mathrm{L}$ to $20,000 \mathrm{ag} / \mu \mathrm{L}$. An isotope-dilution calibration curve was also constructed using the ${ }^{13} C_{12}-2,3,7,8-$ TCDD as the internal standard over the range of $500 \mathrm{ag} / \mu \mathrm{L}$ to $35,000 \mathrm{ag} / \mu \mathrm{L}$. Triplicate measurements produced a good corre- 


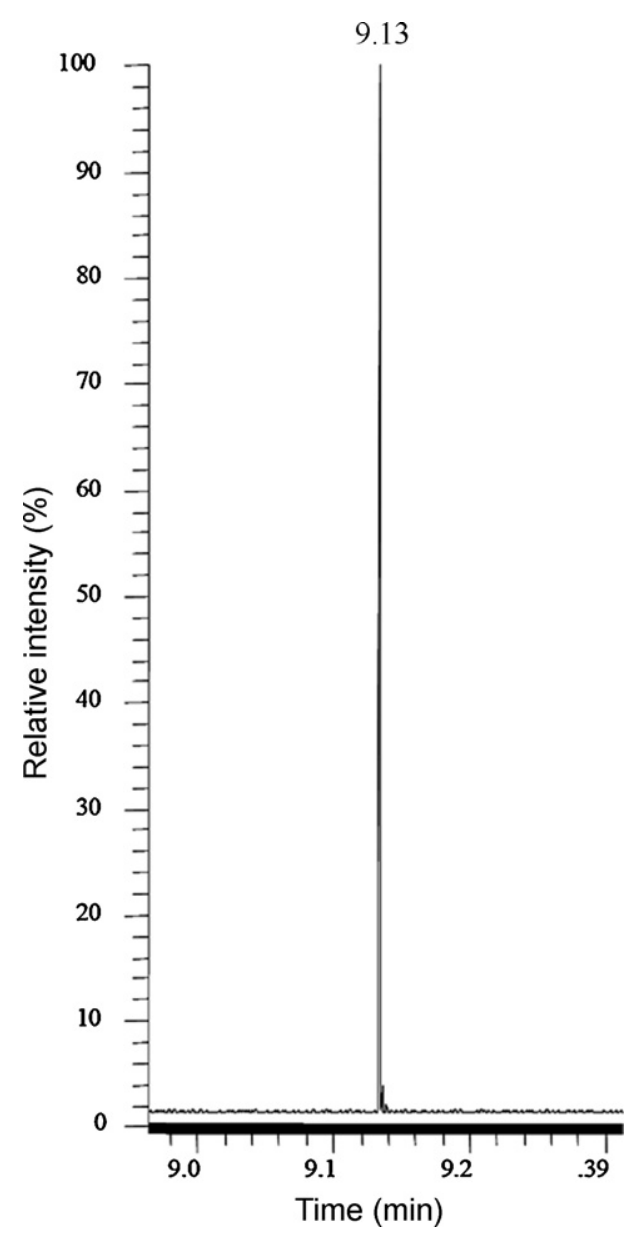

Fig. 1. CZC-GC-IDHRMS measurement of a 2,3,7,8-TCDD standard, only one mass monitored $m / z 321.8936$ [M+2], 1 fg on column, $\mathrm{S} / \mathrm{N}=1420: 1$ (4 sigma).

lation $\left(R^{2}=0.9953\right)$ over this large dynamic range (the relative response factor (RRF) for this curve was 1.75), although variation coefficients were up to $50 \%$ for the lowest calibration points. This limited precision at the low end can partially be attributed to the large difference in concentration between the native and the labeled 2,3,7,8-TCDD (concentration ratio $=0.002$ ). This can be solved by creating special 'ultra-plus trace' standard mixtures capable of covering 2-3 orders of magnitude. Such solutions should be prepared in close collaboration with producers of standards to ensure ultra high purities of labeled solutions and accurate preparation of solutions.

As a next step, to determine the utility of the GC $\times$ GC method for real measurement of PCDDs in serum samples, we used a standard human reference serum-matrix NIST SRM 1589a, which contained only natural levels of dioxins [31]. The major goal was to estimate the potential effect of the serum matrix on the modulated signal in terms of detection limits. Initial experiments with serum samples used the same sample sizes $(10 \mathrm{~g})$ that are normally used for routine GC-HRMS analyses. The serum was prepared using a published extraction and cleanup procedure [26], concentrated to $20 \mu \mathrm{L}$ and further diluted to concentration levels similar to those analyzed in standards. Fig. 3 shows a total ion chromatogram of the tetra- through octa-PCDD congeners. In this figure, it can be seen that a second separation on the ${ }^{2} \mathrm{D}$-section of column seems to occur as a result of the modulation and the reduction of peak width. Experiments on sample extracts from human serum NIST SRM 1589a which were diluted after preparation, also resulted in very low limits of detection. The matrix, expected to be problem-

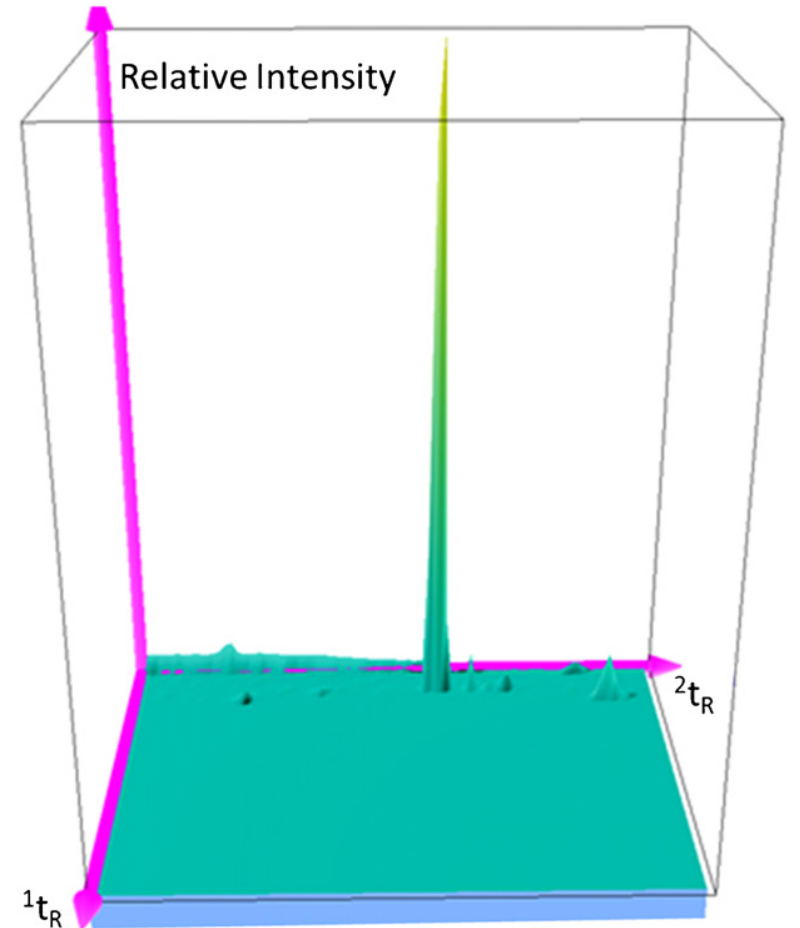

Fig. 2. CZC-GC-IDHRMS measurement of 2,3,7,8-TCDD showing the signal at $\mathrm{m} / \mathrm{z}$ 321.8936 resulting from an injection of a standard containing $313 \mathrm{ag}, \mathrm{S} / \mathrm{N} 400: 1$ (4 sigma).

atic at the long modulation periods used, was not found to be an issue, as illustrated in Fig. 4 for 540 ag of 2,3,7,8-TCDD (the same is true for other congeners, not shown). As an example, on-column injection of a serum extract containing 223 ag of 1,2,3,7,8-PeCDD (70\% recovery rate assumed) resulted in a peak with a $\mathrm{S} / \mathrm{N}$ of $188: 1$ (4 sigma, $m / z=355.8546$ ).

\subsection{Comparison of GC-IDHRMS and CZC-GC-IDHRMS}

In order to minimize variations due to instrumental setup, the same MAT95XP HRMS instrument was equipped with two Agilent $6890 \mathrm{~N}$ gas chromatographs utilizing the dual GC inlet capability of the instrument. One of the GC ovens was equipped for classical 1D GC, the other GC oven was equipped for GC $\times$ GC. We measured 2,3,7,8-TCDD in a diluted extract of SRM 1589a using both the con-

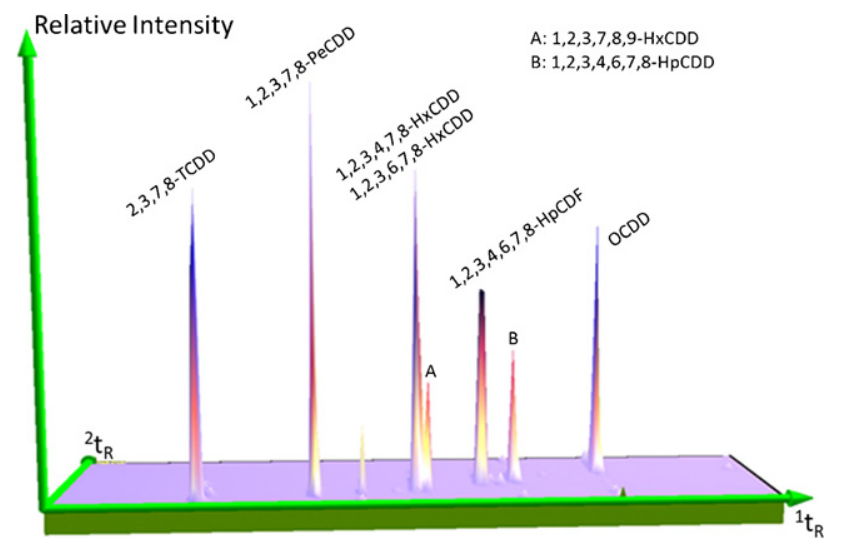

Fig. 3. CZC-GC-IDHRMS 3D plot showing the total ion current (TIC) resulting from an injection of NIST SRM human serum extract in which seven 2,3,7,8-substituted dioxin congeners ( 2 unresolved) and one 2,3,7,8-substituted furan congener were monitored. 
a Relative Intensity
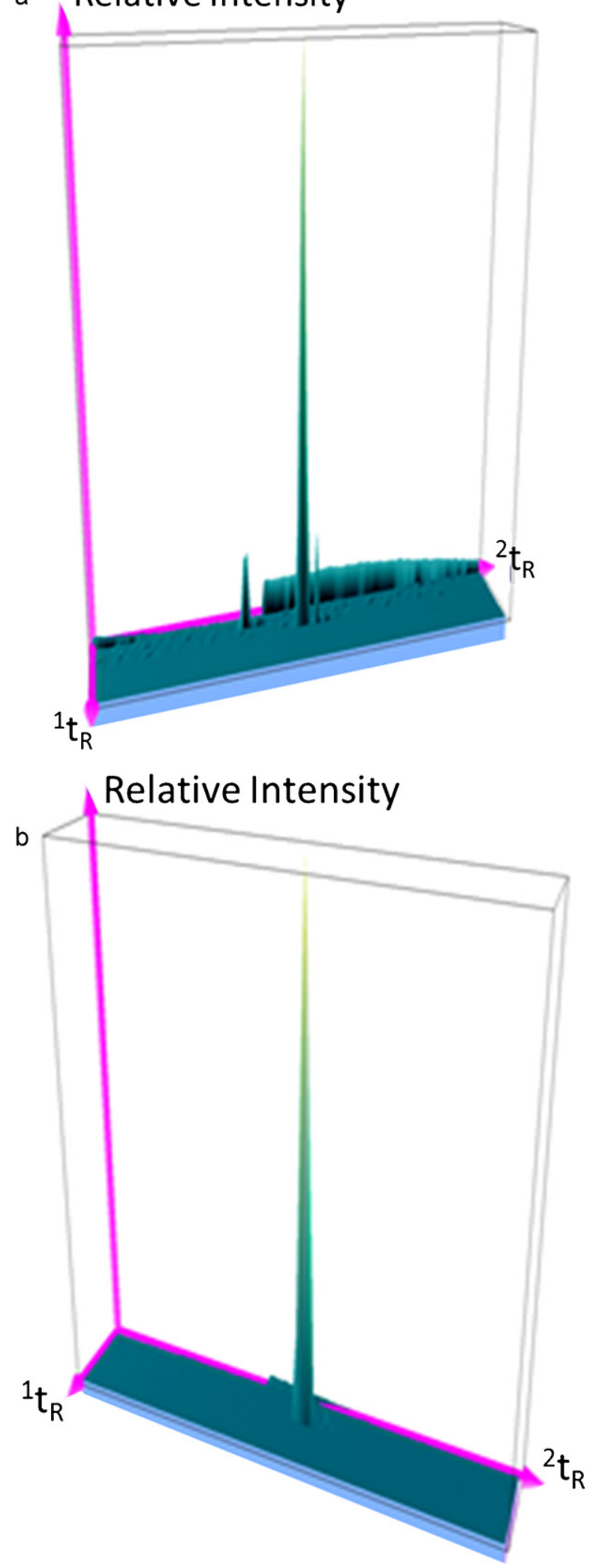

Fig. 4. Plots showing signal at $m / z 319.8965$ (a) and 321.8936 (b) of 2,3,7,8-TCDD resulting from a CZC-GC-IDHRMS injection of NIST SRM 1589a. The human serum extract is equivalent to approximately $540 \mathrm{ag}$, assuming $70 \%$ recovery. ventional GC-IDHRMS and the CZC-GC-IDHRMS techniques with the conditions described in Section 2.

One $\mu \mathrm{L}$ of the diluted human serum extract ( $\sim 4$ fg of $2,3,7,8$ TCDD) was first injected into the single dimensional GC column and measured by HRMS. Following the measurement, another one $\mu \mathrm{L}$ was injected into the CZC column set and measured by HRMS. The results of the two injections are shown in Fig. 5. The conventional GC-IDHRMS was unable to measure 2,3,7,8-TCDD in the extract while the CZC-GC-IDHRMS approach gave a peak with a $\mathrm{S} / \mathrm{N}$ of $600: 1$ for 2,3,7,8-TCDD. The advantage of the CZC approach can also be seen by comparing the peak height measurement of the ${ }^{13} C_{12}-2,3,7,8$-TCDD internal standard which was an order of magnitude larger using the CZC-GC-HRMS approach (Fig. 5). The large increase in the $\mathrm{S} / \mathrm{N}$ ratio is due to the focusing effect of the modulation process which refocuses and sharpens the peak.

Subsequent experiments were conducted on smaller sized samples of NIST SRM 1589a (1-5 g) prepared using the same preparation method usually used for larger samples [26]. In this case the signal resulting from 2,3,7,8-TCDD could still be observed, but the sample matrix was found to be much more problematic under the conditions used. In sample sizes below $4 \mathrm{~g}$ the matrix effect posed a significant problem. The high signal resulting from the matrix was observed in hexane blanks as well as serum samples and thus was deemed to arise from the sample preparation procedure itself. Attempts to circumvent the matrix problem by decreasing the modulation period and lengthening the portion of column used as the ${ }^{2} \mathrm{D}$ column have been only partly successful, and more work will be necessary to optimize this system for analysis of PCDDs in small serum samples. The small samples resulted in a high level of noise associated with the matrix even when injected on a conventional GC-HRMS system. A more comprehensive GC $\times$ GC system with a different ${ }^{2} \mathrm{D}$ column may be helpful, but it is also expected that modifications to the sample preparation method will need to be made, since the majority of the matrix effect observed is seen in the hexane blanks as well as in the serum samples. The miniaturization of the procedure because of the scaling down of the sample size appears to be a key step in the CZC-GC-IDHRMS approach. Reduction of the sample clean-up and fractionation columns has already been successfully reported [27] and could be used in conjunction with recently reported miniaturized pressurized liquid extraction (PLE) [32]. It is interesting to emphasize that even with a lowering of the matrix-solvent noise, it is clear that measuring at such low levels will be extremely dependent of the blank levels. As it was already foreseen by Ferrario et al. more than 10 years ago [33], the establishment of the method LODs will now be limited by the laboratory environment rather than by the instrument sensitivity itself. This background contamination potentially poses a serious problem in terms of defining the limit of detection and quantification above background that can be reliably detected for various samples matrices.

\subsection{CZC-GC-IDHRMS of DDE and BB-153 in standards and human dried-blood spot (DBS) samples}

In view of the interest in the ability to detect environmental contaminants in smaller sample sizes, it was decided to apply the CZC-GC-IDHRMS technique to the measurement of contaminants of interest in human DBS specimens. A report on the analysis of dried-blood spot specimens using GC with electron-capture detection has been published earlier [34] and we have included preliminary data here using CZC-GC-IDHRMS to show the utility of the $\mathrm{GC} \times \mathrm{GC}$ technique for small sample sizes. A CZC method was developed (to be reported separately) to analyze standards and blood spot samples for DDE and BB153. Again, results with standards were very impressive, showing considerable enhancement in sensitivity over that observed using the conventional GC-IDHRMS 

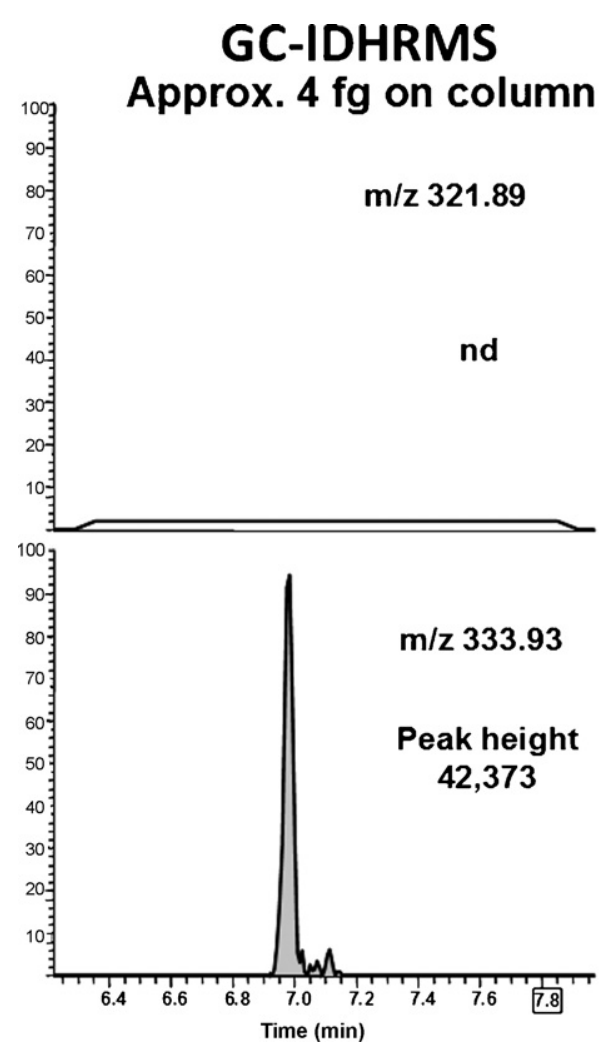

\section{CZC-GC-IDHRMS} Approx. 4 fg on column
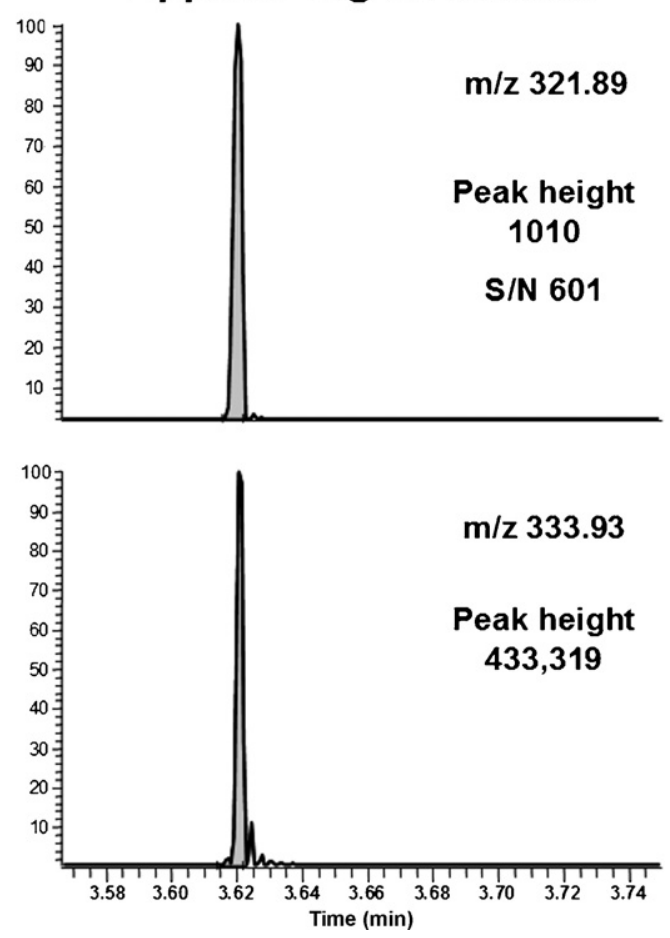

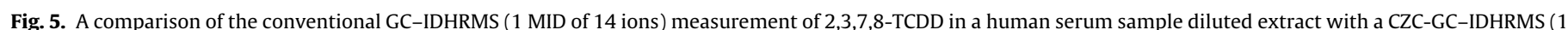

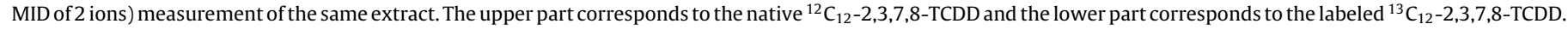

technique. For example, injection of a standard containing $200 \mathrm{fg}$ of BB153 resulted in a S/N of 5,027:1 for the signal at $m / z 546.6189$ ion, corresponding to the loss of one ${ }^{81} \mathrm{Br}$ atom from the $\mathrm{M}+6$ parent ion at $m / z 627.5352$.

Application of the CZC-GC-IDHRMS technique to human DBS samples resulted in far less difficulty with matrix effects than was observed with the PCDDs in serum. The technique was first applied to analysis of spiked DBS samples and then to analysis of actual unknown specimens (results to be reported separately). In both cases the samples were analyzed by conventional GC-HRMS as well as by CZC-GC-IDHRMS. The CZC-GC-IDHRMS method was very rapid, analyzing samples for both BB-153 and DDE and the external standard, ${ }^{13} \mathrm{C}_{6}-1,2,3,4-\mathrm{TCDD}$ in about six minutes. The results from the CZC technique with DBS specimens also showed enhanced sensitivity when compared with the Thermo Electron DFS HRMS, which is three to five times more sensitive than the MAT95XP [35]. Fig. 6 shows a comparison of the same unspiked blood spot sample extract analyzed by GC-IDHRMS (DFS) and by CZC-GC-IDHRMS using the MAT95. The sensitivity enhancement for measuring DDE using the CZC system is evident by comparing the $\mathrm{S} / \mathrm{N}$ ratios for DDE in Fig. 6.

\subsection{Challenges in performing analyses at sub-ultra-trace levels}

During these experiments, we observed significant ion ratio skewing for the low end of the working range. The most likely explanation for this is that very few ions actually reach the detector when working at the attogram level. Therefore, one can imagine that the ion statistics cause the measured isotopic ratio to fail normal QA/QC threshold of $\pm 20 \%$ from theoretical values. Considering an average human serum sample of $0.5 \%$ lipids with a level of $1 \mathrm{pg} / \mathrm{g}$ lipids for 2,3,7,8-TCDD. A sample size of $2 \mathrm{~g}$ would represent $10 \mathrm{fg}$ of 2,3,7,8-TCDD, or approximately $2 \times 10^{7}$ molecules of 2,3,7,8-TCDD. Taking into account a recovery rate of $50 \%$ and the splitless injec- tion of $1 \mu \mathrm{L}$ from $5 \mu \mathrm{L}$, this corresponds to $2 \times 10^{6}$ molecules that are entering the GC-MS system. This can be extrapolated to what actually enters the ion source of the MS instrument. If we consider a $1 \%$ ionization efficiency, a $50 \%$ survival of the parent ion after fragmentations, a $10 \%$ overall transmittance into the mass analyser, 5 acquisition cycles per peak, and $10 \mathrm{~ms}$ dwell time every $40 \mathrm{~ms}$, the number drops to less than 50 molecules of TCDD available at the detector for ion ratio calculations. Such a limited number of molecules could probably be a limitation to allow proper ion statistics to take place.

Investigations on the lock mass dwell time minimum requirements and influence on mass accuracy were also carried out because interferences could also be due to partial minimal coelution with other analytes that could be much higher in concentration. As an example, one needs a resolution of at least 8000 to differentiate between ${ }^{12} \mathrm{C}-2,3,7,8$-TCDD and ${ }^{13} \mathrm{C}-2,3,7,8-\mathrm{TCDF}$ (Table 2). Although the interfering ions from ${ }^{13} \mathrm{C}-2,3,7,8-\mathrm{TCDF}$ are less abundant isotopically, their concentrations are two orders of magnitude higher, which makes them from 100 to 650 times more intense than ${ }^{12} \mathrm{C}-2,3,7,8$-TCDD ions. A similar, and chromatographically as relevant, situation is present with PCB-126. Further research is needed to ensure proper understanding of those low end deviations and to solve this issue.

\section{Summary and conclusions}

The use of a GC $\times$ GC loop modulator to perform CZC-GC coupled with IDHRMS has been shown to be the most sensitive method available for the measurement of certain environmental contaminants in human samples. In the current study, the sensitivity enhancement alone has been considered; no advantage has even yet been taken from the second dimension separation power. The preliminary data on blood spots are promising and open those samples to environmental contaminants analyses like never before. 

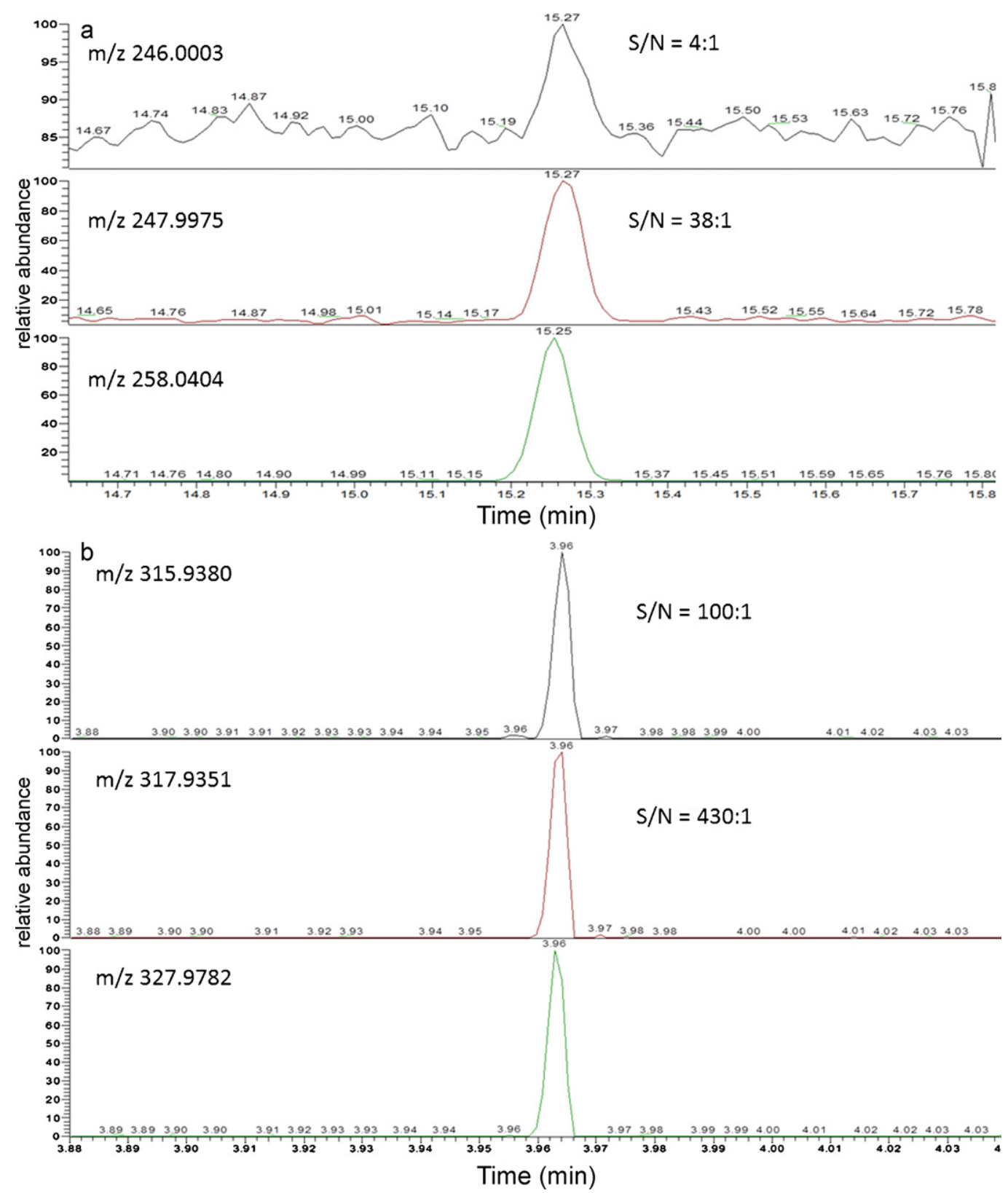

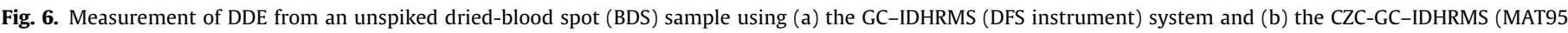

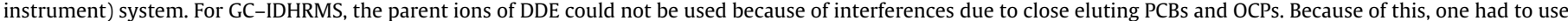

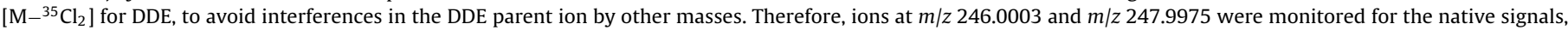

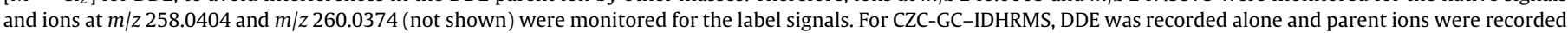

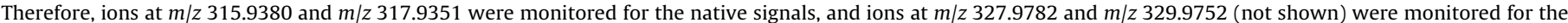
label signals.

Table 3 lists the sensitivity for 2,3,7,8-TCDD using various GC and mass spectrometry combinations. Further development and application of this technique, especially to the analysis of human dried-blood spot samples, could yield unprecedented sensitivity for rapid and routine screening of human specimens for the presence of environmental contaminants. Table 4 depicts the current state-of-the-art in being able to measure approximately 586,000 2,3,7,8-TCDD molecules.

The use of the CZC-GC technique with a newer, more sensitive mass spectrometer, such as the Thermo Electron DFS, would further enhance the sensitivity of this approach. However, a strategy has to be proposed to ensure miniaturization of the sample

Table 2

Resolution required to separate the $\mathrm{M}+4$ and $\mathrm{M}+6$ ions for the ${ }^{13} \mathrm{C}-2,3,7,8-\mathrm{TCDF}$ internal standard from the $\mathrm{M}$ and $\mathrm{M}+2$ ions for ${ }^{12} \mathrm{C}-2,3,7,8-\mathrm{TCDD}$

\begin{tabular}{|c|c|c|c|c|c|c|}
\hline Specie & Mass & Required resolution & Ion in cluster & Isotope abundance & Level $(\mathrm{pg} / \mu \mathrm{l})$ & Specie ratio \\
\hline${ }^{12} \mathrm{C}-2,3,7,8-\mathrm{TCDD}$ & 321,8930 & & $\mathrm{M}+2$ & $100 \%$ & 0.05 & 1 \\
\hline${ }^{13} \mathrm{C}-2,3,7,8-\mathrm{TCDF}$ & 321,9325 & $>8000$ & $M+6$ & $10 \%$ & 50 & 100 \\
\hline${ }^{12} \mathrm{C}-2,3,7,8-\mathrm{TCDD}$ & 319,8960 & & M & $75 \%$ & 0.05 & 1 \\
\hline${ }^{13} \mathrm{C}-2,3,7,8-\mathrm{TCDF}$ & 319,9354 & $>8000$ & $M+4$ & $50 \%$ & 50 & 650 \\
\hline
\end{tabular}


Table 3

Analytical sensitivity for 2,3,7,8-TCDD using various GC-MS approaches.

\begin{tabular}{|c|c|c|c|}
\hline Technique & Sample & Amount on column & $\mathrm{S} / \mathrm{N}$ (4 sigma) \\
\hline GC (MAT95XP)-HRMS & Standard & $20 \mathrm{fg}$ & 43 \\
\hline GC (DFS)-HRMS & Standard & $20 \mathrm{fg}$ & 604 \\
\hline CZC-GC (MAT95XP)-HRMS & Standard & $313 \mathrm{ag}$ & 400 \\
\hline CZC-GC (MAT95XP)-HRMS & Serum & $325 \mathrm{ag}$ & 161 \\
\hline GC $\times$ GC-LRTOFMS & Standard & $500 \mathrm{fg}$ & 6 \\
\hline
\end{tabular}

Table 4

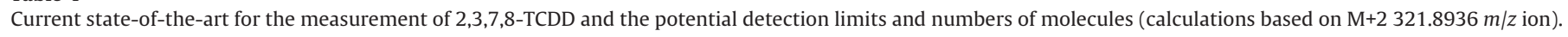

\begin{tabular}{|c|c|c|c|}
\hline Quantity & Notation & Number of moles & Number of molecules \\
\hline 1 nanogram (ng) or $10^{-9} \mathrm{~g}$ & $\mathrm{ppb}$ & $3.1 \times 10^{-12}$ (3,1 picomoles) & $1,870,000,000,000\left(1.87 \times 10^{12}\right)$ \\
\hline 1 picogram (pg) or $10^{-12} \mathrm{~g}$ & ppt & $3.1 \times 10^{-15}(3,1$ femtomoles $)$ & $1,870,000,000\left(1.87 \times 10^{9}\right)$ \\
\hline 1 femtogram (fg) or $10^{-15} \mathrm{~g}$ & ppq & $3.1 \times 10^{-18}$ (3,1 attomoles) & $1,870,000\left(1.87 \times 10^{6}\right)$ \\
\hline 313 attogram (ag) or $10^{-18} \mathrm{~g}$ & ppquint & $9.7 \times 10^{-19}$ (972 zeptomoles) & $586,000\left(5.86 \times 10^{5}\right)$ \\
\hline 1 attogram (ag) or $10^{-18} \mathrm{~g}$ & ppquint & $3.1 \times 10^{-21}(3,1$ zeptomoles $)$ & $1,870\left(1.87 \times 10^{3}\right)$ \\
\hline 1 zeptogram $(\mathrm{zg})$ or $10^{-21} \mathrm{~g}$ & ppsext & $3.1 \times 10^{-24}(3,1$ yoctomoles $)$ & 1,87 \\
\hline 1 yoktogram (yg) or $10^{-24} \mathrm{~g}$ & ppsept & $3.1 \times 10^{-27}$ (3,1 'phantomoles') & $<1$ \\
\hline
\end{tabular}

Bold is current state-of-the-art.

preparation procedure, and proper monitoring and control of the laboratory environment in terms of blanks. Once such a complete method would be available, it would be extremely valuable for considering biomonitoring studies in which baby and child are targeted. DBS samples taken at early stages of life could systematically be screened for major toxicants or stored until particular health problem would appear at the adult stage, to try to link particular pathology to exposures that occurred years earlier.

\section{References}

[1] E.W. Turner, S.M. Welch, E.S. DiPietro, T.P. Cash, P.C. McClure, L.L. Needham, D.G. Patterson Jr., Organohalogen Compd. 66 (2004) 262.

[2] D.G. Patterson Jr., L. Hampton, C.R. Lapeza Jr., W.T. Belser, V. Green, L. Alexander, L.L. Needham, Anal. Chem. 59 (1987) 2000.

[3] A. Baccarelli, A.C. Pesatori, D. Consonni, P. Mocarelli, D.G. Patterson Jr., N.E. Caporaso, P.A. Bertazzi, M.T. Landi, Chemosphere 60 (2005) 898.

[4] J.B. Phillips, D. Luu, J.B. Pawliszyn, G.C. Carle, Anal. Chem. 57 (1985) 2779.

[5] Z. Liu, J.B. Phillips, J. Microcol. Sep. 6 (1994) 229.

[6] J.B. Phillips, J. Beens, J. Chromatogr. A 856 (1999) 331.

[7] J. Beens, U.A.Th. Brinkman, Trends Anal. Chem. 19 (2000) 260.

[8] M. Adahchour, J. Wiewel, R. Verdel, R.R. Vreuls, U.A.Th. Brinkman, J. Chromatogr. A 1086 (2005) 99.

[9] G.S. Frysinger, R.B. Gaines, C.M. Reddy, Environ. Forensics 3 (2002) 27.

[10] J.-F. Focant, E.J. Reiner, K. MacPherson, T. Kolic, A. Sjödin, D.G. Patterson Jr., S.L. Reese, F.L. Dorman, J.W. Cochran, Talanta 63 (2004) 1231.

[11] J.-F. Focant, G. Eppe, M.-L. Scippo, A.-C. Massart, C. Pirard, G. Maghuin-Rogister, E. De Pauw, J. Chromatogr. A 1086 (2005) 45.

[12] J.-F. Focant, A. Sjödin, W.E. Turner, D.G. Patterson Jr., Anal. Chem. 76 (2004) 6313.

[13] J. Beens, H. Boelens, R. Tijssen, J. Blomberg, J. High Resolut. Chromatogr. 21 (1998) 47.

[14] H.-J. de Geus, J. de Boer, J.B. Phillips, E.B. Ledford Jr., U.A.Th. Brinkman, J. High Resolut. Chromatogr. 21 (1998) 411.

[15] A. Lee, K.D. Bartle, A.L. Lewis, Anal. Chem. 73 (2001) 1330.

[16] P. Korytar, P.E.G. Leonards, J. de Boer, U.A.Th. Brinkman, J. Chromatogr. A 958 (2002) 203.
[17] J. Dallüge, R. Vreuls, J. Beens, U.A.Th. Brinkman, J. Sep. Sci. 25 (2002) 201.

[18] M. Kalio, T. Hyoetylaeinen, J. Chromatogr. A 1148 (2007) 235.

[19] K. Banerjee, S.H. Patil, S. Dasgupa, D. Oulkar, S.B. Patil, R. Savant, P.G. Adsule, J. Chromatogr. A 1190 (2008) 350.

[20] Z. Liu, S.R. Sirimanne, D.G. Patterson Jr., L.L. Needham, J.B. Phillips, Anal. Chem. 66 (1994) 3086.

[21] E.B. Ledford Jr., C. Billesbach, J. High Resolut. Chromatogr. 23 (2000) 202

[22] J. Beens, M. Adahchour, R.J.J. Vreuls, K. van Altena, U.A.Th. Brinkman, J. Chromatogr. A 919 (2001) 127.

[23] E.B. Ledford Jr., J.R. TerMaat, C.A. Billesbach, Technical note KT030606-1, What is loop modulation? Available at http://www.zoex.com/applications/ technical_notes.asp.

[24] D.G. Patterson Jr., J.B. Barr, E.S. DiPietro, J. Grainger, V.E. Green, C.R. Lapeza Jr., V.L. Maggio, S. Sirimanne, W.E. Turner, Organohalogen Compd. 27 (1996) 309.

[25] J. Grainger, J.-M.D. Dimandja, V. Green, Z. Liu, D.G. Patterson Jr., Organohalogen Compd. 35 (1998) 28A.

[26] W.E. Turner, E.S. DiPietro, T.P. Cash, P.C. McClure, D.G. Patterson Jr., H. Shirkhan, Organohalogen Compd. 19 (1994) 31.

[27] J.-F. Focant, G. Eppe, A.-C. Massart, G. Scholl, C. Pirard, E. De Pauw, J. Chromatogr. A 1130 (2006) 97.

[28] D.G. Patterson Jr., W.E. Turner, Laboratory Procedure for Measurement of PCBs and PCDDs/PCDFs/cPCBs in Serum by HRGC/ID-HRMS, Method 28, Division of Laboratory Sciences, National Center for Environmental Health, Centers for Disease Control and Prevention, Atlanta, GA, 2006.

[29] J. Dalluge, R.J.J. Vreuls, D. van Iperen, M. van Rijn, U.A.Th. Brinkman, J. Sep. Sci. 25 (2002) 608.

[30] M. Van den Berg, L. Birnbaum, M. Denison, M. DeVito, W. Farland, M. Feeley, H. Fiedler, H. Hakansson, A. Hanberg, L. Haws, M. Rose, S. Safe, D. Schrenk, C. Tohyama, A. Tritscher, J. Tuomisto, M. Tysklind, N. Walker, R.E. Peterson, Toxicol. Sci. 93 (2006) 223.

[31] Certificate of Analysis, SRM 1589a PCBs, Pesticides, and Dioxins/Furans in Human Serum, NIST, 2000.

[32] J.J. Ramos, C. Dietz, M.J. González, L. Ramos, J. Chromatogr. A 1152 (2007) 254.

[33] J. Ferrario, C. Byrne, A.E. Dupuy Jr., Chemosphere 34 (1997) 2451.

[34] V.W. Burse, M.R. DeGuzman, M.P. Korver, A.R. Najam, C.C. Williams, W.H. Hannon, B.L. Therrell, Biochem. Mol. Med. 61 (1997) 236.

[35] W.E. Turner, S.M. Welch, E.S. DiPietro, W.E. Whitfield, T.P. Cash, P.C. McClure, L.L. Needham, D.G. Patterson Jr., Organohalogen Compd. 68 (2006) 2477. 